\title{
Investigating Miranda Waiver Decisions: An Examination of the Rational Consequences
}

\author{
Hayley L. Blackwood, Richard Rogers, Jennifer A. Steadham and Chelsea E. Fiduccia
}

University of North Texas

\begin{abstract}
Author Note
This study was supported by grant \#1219430 from Law and Social Sciences Program, National Science Foundation to Richard Rogers as the principal investigator. Any opinions, findings, and conclusions, or recommendations expressed in this material are those of the authors and do not necessarily reflect the views of the National Science Foundation.

Financial disclosure: Richard Rogers receives royalties on the Miranda Reasoning Measure (MRM) and the Miranda Vocabulary Scale (MVS) from Psychological Assessment Resources, Inc.

Correspondence regarding this article should be addressed to Hayley L. Blackwood, blackwoodhayley@yahoo.com.
\end{abstract}




\begin{abstract}
Millions of custodial suspects waive their Miranda rights each year without the benefit of legal counsel. Miranda understanding, appreciation, and reasoning abilities are essential to courts' acceptance of Miranda waivers (Grisso, 2003; Rogers \& Shuman, 2005). The question posed to forensic psychologists and psychiatrists in disputed Miranda waivers is whether a particular waiver decision was knowing, intelligent, and voluntary. Despite the remarkable development of Miranda research in recent decades, studies have generally focused on understanding and appreciation of Miranda rights, but with comparatively minimal emphasis on Miranda reasoning and attendant waiver decisions. Research on defendants' decisional capacities constitutes a critical step in further developing theoretical and clinical models for Miranda waiver decisions. The current study evaluated Miranda waiver decisions for 80 pretrial defendants from two Oklahoma jails to study systematically how rational decision abilities affect defendants' personal waiver decisions. In stark contrast to what was expected, many defendants were able to identify a rational decisional process in their own legal cases, yet cast such reasoning aside and chose a completely contradictory Miranda waiver decision.
\end{abstract}

Key words: Miranda, Miranda rights, waiver decisions, Standardized Assessment of Miranda Abilities 


\section{Investigating Miranda Waiver Decisions: An Examination of the Rational Consequences}

In Miranda v. Arizona (1966), the Supreme Court of the United States affirmed that "an individual held for interrogation must be clearly informed that he has the right to consult with a lawyer and to have the lawyer with him during interrogation." The Court specified that "as with the warnings of the right to remain silent and that anything stated can be used in evidence against him, this warning is an absolute prerequisite to interrogation." Moreover, the Court disallowed any inferences from custodial suspects regarding their knowledge of Miranda rights, concluding that "no amount of circumstantial evidence that the person may have been aware of this right will suffice to stand in its stead," inasmuch as "only through such a warning is there ascertainable assurance that the accused was aware of this right" (pp. 471-472).

Embodying this conclusive affirmation of the $5^{\text {th }}$ Amendment privilege against selfincrimination, Miranda warnings have continued to serve for the last four decades as the primary procedural safeguard for custodial suspects. The centrality and longevity of Miranda warnings are especially noteworthy because the Supreme Court of the United States never intended the warnings to be a "constitutional straitjacket" (Miranda, p. 467) and was very open to "other fully effective means" (p. 479) of ensuring the $5^{\text {th }}$ Amendment privilege. With a proactive stance, the Court encouraged legislative bodies to "continue their laudable search for increasingly effective ways of protecting the right of the individual while promoting efficient enforcement of our criminal laws" (p. 467).

Miranda did not herald a change in the existing law as much as it served to explicate key elements for the benefit of law enforcement officers and prosecutors. For example, just two years earlier in Escobedo v. Illinois (1964), the Court "dealt with certain phases" (Miranda, 1964, p. 440) of police procedures that were likely to result in constitutionally inadmissible statements, 
but it did not prescribe a method for warning custodial suspects of their rights during such interrogations. Again, it is important to bear in mind that the Court in Miranda did not supply the specific language of these warnings, but rather a description of its core components. Reflecting a decade and a half later upon the lack of requisite language for Miranda warnings, the Court commented that "no talismanic incantation was required to satisfy its strictures" (California $v$. Prysock, 1981, p. 359).

\section{Overview of Miranda Waivers}

The Miranda decision addressed more than the need to warn custodial suspects of their rights; it also established criteria for a valid relinquishment of those rights—specifically, by requiring that such waivers be made "voluntarily, knowingly and intelligently" (p. 444). The Supreme Court of the United States has consistently upheld these criteria, although in Colorado v. Connelly (1986) it subsequently narrowed the determination of voluntariness to focus upon externally imposed forces by asserting that "the sole concern of the Fifth Amendment, on which Miranda was based, is governmental coercion" (p. 170). Although coercive activity by the police may differentially impair the volitional abilities of defendants with mental disorders - thus implicating the notion of whether a privilege was waived "voluntarily"-most forensic psychological Miranda waiver determinations focus primarily on the "knowingly" and “intelligently" prongs of this test (Rogers \& Shuman, 2005).

Interestingly, the knowing and intelligent prongs sometimes appear to be blended into a single standard rather than treated as distinct—albeit related-determinations. Johnson v. Zerbst (1938) and Edwards v. Arizona (1981) are examples of cases in which the Supreme Court of the United States generally construed these notions as simply comprising a basic awareness or knowledge of one's legal rights. Even more concretely, the Supreme Court of Illinois held in 
People v. Bernasco (1990) that a waiver was both knowing and intelligent as long as the defendant possessed an accurate understanding of the words used in the Miranda warnings. A much more stringent conceptualization of what constitutes a valid Miranda waiver is outlined in Fare v. Michael C. (1979). In this case, the Supreme Court of the United States identified three requisite elements: whether a suspect "has the capacity to understand the warnings given to him, the nature of his Fifth Amendment rights, and the consequences of waiving those rights" (p. 725). This particularized test requires a globally adequate understanding of the constitutional protections against self-incrimination as well as the consequences associated with Miranda waiver decisions.

The requirement that custodial suspects understand the consequences of a Miranda waiver was addressed by the Supreme Court of the United States in two subsequent decisions. In Colorado v. Spring (1987), the Court held that valid Miranda waivers require a "full awareness both of the nature of the right being abandoned and the consequences of the decision to abandon it" (p. 573), while in Moran v. Burbine (1986) the Court required even more explicitly that the custodial suspect be "aware of the State's intention to use his statements to secure a conviction" (p. 422).

Beyond knowledge, appellate decisions have grappled with the minimum level of rational ability required for intelligent waivers. In Iowa v. Tovar (2004), the Supreme Court of the United States emphasized that fully informed choices are what form the rational basis for intelligent Miranda waivers, requiring - on the basis of a principle established at least as early as the Court's decision in Adams v. U.S. (1942) — that the custodial suspect "knows what he is doing and his choice is made with eyes open" (Tovar, p. 88). The Court in Tovar ultimately concluded that an unawareness of the consequences typically associated with waiving counsel (e.g., risks of 
a poor legal defense and of being deprived of the right to seek legal counsel before making important legal decisions) resulted in a waiver that was not sufficiently knowing and intelligent.

The Supreme Court of the United States held in Godinez v. Moran (1993) that defendants must demonstrate "the capacity for reasoned [emphasis added] choice among the alternatives" (p. 389), and later elaborated in U.S. v. Ruiz (2002) that the complex task of waiving one's Miranda rights requires more than a mere abstract understanding of relevant rights. Thus, essential to a valid waiver is comprehension of how such rights apply to one's own legal circumstances.

Born from controversy, Miranda v. Arizona (1966) retains its iconic stature in the criminal law after a span approaching half a century, and seems likely to do so for the foreseeable future. Valid waiver of one's Miranda rights must be knowing, intelligent, and voluntary - a test that in many cases will compel counsel to obtain a forensic psychological evaluation of the defendant's capacity for relevant reasoning.

\section{Research on Miranda Reasoning}

Miranda reasoning abilities have rarely been empirically evaluated, although they are featured prominently in legal (Godinez v. Moran, 1993; Iowa v. Tovar, 2004) and clinical (Grisso, 2003; Rogers \& Shuman, 2005) conceptualizations of valid Miranda waivers. Policyrelevant empirical research on Miranda reasoning is challenged by the absence of both clearly defined legal definitions and standardized assessment instruments. Grisso's (1981) trail-blazing research establishes a core foundation for the measurement of intelligent Miranda waivers. His seminal study assessed how juveniles with felony arrests applied legal rights to hypothetical situations. Using the Function of Rights in Interrogation (FRI), these juvenile were asked questions relevant to their rights to silence and counsel and to the nature of interrogation. With 
further research, the FRI is now included in the Miranda Rights Comprehension Instruments (MRCI; Goldstein, Zelle, \& Grisso, 2012).

Using the FRI with adult probationers, Grisso's (1998, p. 6) research examined how they may fail to "grasp the significance of the warnings" as applied to the adversarial nature of the interrogation and their rights to silence and counsel. For the right to silence, Grisso found that $21.7 \%$ of offenders failed to understand this "right" as a Constitutional safeguard (i.e., could not be punished or prosecuted for exercising this right). If silence is perceived as incriminating, then offenders may reason that they have nothing to lose by talking (Rogers \& Drogin, in press). Even more concerning, $42.9 \%$ believed a judge could revoke their right to silence. Surely, a revocable safeguard is no safeguard at all.

An investigation by Rogers, Harrison, Hazelwood, and Sewell (2007) examined common reasons for exercising and waiving Miranda rights using a sample of mentally disordered defendants participating in an inpatient competency restoration program. Not surprisingly, substantial numbers of these defendants lacked the basic ability to generate reasons for their own waiver decisions. Even when reasons were given, the basic reasoning underlying them was often, at best, questionable. Common but dubious reasons for waiving rights included (a) an ability to handle the case alone (19.6\%), (b) an ability to prove one's innocence (17.8\%), and (c) an inability to afford counsel (17.8\%) — this final reason demonstrates the incapacity to rationally apply the "free legal services" component of Miranda to their own cases. For exercising rights, the clear majority understood that it would avoid incrimination (63.6\%), whereas most (83.2\%) saw the need for legal expertise. Several declared reasons for not exercising rights appeared less rational, such as avoiding further charges $(6.5 \%)$ or being punished with even harsher sentences $(8.4 \%)$. 
Rogers, Sewell, Drogin and Fiduccia (2012) developed and validated the Miranda Reasoning Measure (MRM) as a systematic method to assess suspects' ability to reason about exercising or waiving their rights. It is indebted to Grisso's (1981) scoring of the Waiver Expectancy Interview with its dual focus on short- and long-range consequences. This differentiation is essential because many defendants engage in temporal discounting (Rogers \& Shuman, 2005); that is, they may value immediate benefits (e.g., coffee) over life-changing consequences (e.g., felony conviction). Incorporating this time-oriented perspective, the MRM has four scoring categories: (a) "0" for impaired reasoning (i.e., delusional or self-defeating) or a damaging factual error that compromises reasoning (e.g., unavailability of counsel for an indigent defendant); (b) "1" for an unclear reason that is not obviously impaired; (c) "2" for a clear reason that only takes into account immediate circumstances; and (d) "3" for a clear reason that explicitly takes into account long-range considerations. The MRM covers four content areas: Defendants identified pros ("good reasons") and cons ("possible problems") with respect to exercising and waiving their Miranda rights. Even during the MRM's initial conceptualization, however, an important asymmetry was observed. Specifically, custodial suspects are assessed concerning their competency to waive their rights. The asymmetry occurs because suspects are never evaluated regarding their competency to exercise their rights.

Rogers et al. (2012, p. 101, Table 7.22) found that poor Miranda vocabulary produced the largest effect sizes between failed and adequate Miranda reasoning for MRM waiver $(d=0.66)$ and exercise $(d=0.81)$ decisions. For the same comparisons, intelligence and Miranda comprehension provided better discrimination for exercising ( $d$ s of 0.70 and 0.44 ) than waiving ( $d$ s of 0.36 and 0.04 ) MRM items. For a review of the integration of MRM results with other 
Miranda measures, see Standardized Assessment of Miranda Abilities (SAMA; Rogers et al., 2012).

\section{Current Study}

We examined rational models of legal decision-making as propounded by leading scholars for determining a defendant's best-reasoned decision. Models included Bonnie (1992, 1993), Grisso (1997, 2003), Hilgendorf and Irving (1981), and Rogers and Shuman (2005).

Commonalities across models included (a) identification of alternatives and (b) the consequences associated with each alternative. ${ }^{1}$ In an effort to quantify Miranda reasoning, two other issues must be considered, which include ratings of (c) the desirability of each consequence, and (d) the likelihood of each consequence. A rational-consequences score can be calculated for each desired outcome by multiplying (c) and (d). The primary research question is whether defendants apply their rational abilities to their Miranda waiver decisions.

\section{Method}

The present investigation is part of a five-year programmatic research on Miranda warnings and waivers, supported by the National Science Foundation's Law and Social Sciences Program. The current study is based on dissertation data by Blackwood (2013) and consists of original analyses.

\section{Sample}

The Okmulgee County and Cherokee County Detention Centers serve predominantly rural counties that are bordered by Tulsa, Oklahoma. These pretrial detainees $(N=80)$ were recruited through the cooperation of their Oklahoma Indigent Defense System (OIDS) attorneys.

\section{Measures}

\footnotetext{
${ }^{1}$ Bonnie (1992) was also concerned that defendants could "appreciate the significance of that information in his or her case" (p. 305, emphasis in the original).
} 
Pretrial defendants were administered an extensive battery of measures for assessing cognitive abilities and psychological functioning, in addition to forensic measures for specifically assessing Miranda-related abilities. Administration of this battery typically required approximately three hours in duration. As part of programmatic research, two cognitive measures (WASI and WIAT-II) were administered, which were the current versions during the period of data collection. The measures central to the current investigation are summarized below. ${ }^{2}$

Schedule of Affective Disorders and Schizophrenia - Change Version (SADS-C). The SADS-C (Spitzer \& Endicott, 1978a) is a semi-structured interview for assessing the severity and impairment associated with psychopathology. The SADS-C has demonstrated excellent interrater reliability $(M \mathrm{ICC}=.95)$, and its clinical scales (i.e., Psychosis, Mania, Dysphoria, and Insomnia) have exhibited a good model fit $(\mathrm{CFI}=.92$; RCFI $=.95)$ for use with jail samples (Rogers, Jackson, Salekin, \& Neumann, 2003).

Wechsler Abbreviated Scale of Intelligence (WASI). The WASI (Wechsler, 1999) is a brief, well-validated test that assesses intellectual functioning for two domains (verbal and nonverbal abilities) as reflected in four different scales (Vocabulary, Similarities, Block Design, and Matrix Reasoning). The WASI has exhibited similarly excellent estimates of reliability (i.e., $r \mathrm{~s}>.90)$ and concurrent validity with the full-length WAIS-III ( $r=.92$; Wechsler, 1997).

Wechsler Individual Achievement Test $-2^{\text {nd }}$ Edition (WIAT-II). The WIAT-II (Wechsler, 2002) is a measure of academic achievement that produces standard scores and grade equivalents

\footnotetext{
${ }^{2}$ Other measures were administered as part of this programmatic Miranda research, such as Consideration of Future Consequences (CFC; Strathman, Glleicher, Boninger, \& Edwards, 1994); Cognitive Appraisal of Risky Events (CARE; Fromme, Katz, \& Rivet, 1997); Mini International Neuropsychiatric Interview (MINI; Sheehan et al., 1998); Neurobehavioral Cognitive Status Examination (Cognistat; Keiran, Mueller, Langston, \& Van Dyke, 1987); Miranda Acquiescence Scale (MAQ; Rogers et al., 2012); and the Gudjonsson Confession Questionnaire-Revised (GCQ-R; Gudjonsson \& Sigurdsson, 1999).
} 
for both reading and listening comprehension. The WIAT-II has been extensively validated with adult populations and yields high subtest reliabilities (i.e., $r$ s from .80 to .98 ).

Function of Rights in Interrogation (FRI). The FRI (Grisso, 1998) assesses examinees' perceptions of the intended functions of legal procedures on three scales related to Miranda appreciation: (a) Nature of the Interrogation, (b) Right to Counsel, and (c) Right to Silence. Based upon responses to four hypothetical vignettes, 15 questions are scored on a three point scale $(0=$ inadequate response; 1 = questionable response; 2 = adequate response), with total scores ranging from 0 to 30. The FRI benefits from normative data for samples of juvenile and adult offenders and has excellent reliability. It continues to be used without modification in the MRCI (Goldstein et al., 2012).

Miranda Statements Scale (MSS). A revised version of the MSS (Rogers, 2005) evaluates comprehension of representative Miranda components that are designed to comport with three discrete reading levels: easy $\left(<6^{\text {th }}\right.$ grade), moderate (grade $\left.8.0-9.9\right)$, and difficult $\left(\geq 12^{\text {th }}\right.$ grade) For construct validity, a prototypical analysis was conducted by asking three Miranda experts to select representative Miranda warning versions at each reading level. Rogers, Harrison, Shuman et al. (2007) reached a high level of agreement (98.3\%) for prototypical components after three iterations. The MSS has a high level of interrater reliability (mean $r=.91$ ).

Miranda Vocabulary Scale (MVS). The MVS (Rogers, Hazelwood, Sewell, Blackwood, Rogstad, \& Harrison, 2009; Rogers et al., 2012) is a 36-item measure that evaluates knowledge of Miranda-related vocabulary words (e.g., "right" and "lawyer"). Each item is scored on a 5point scale: 0 = incorrect; $1=$ correct definition or use of the word in a sentence, but irrelevant to Miranda; $2=$ correct use of the word in a sentence and relevant to Miranda; $3=$ partially correct Miranda-relevant definition; 4 = correct definition and relevant to Miranda. The MVS has 
exhibited excellent interrater reliability $(r=.99)$ in addition to good convergent and discriminant validity (Rogers et al., 2012).

Miranda Reasoning Measure (MRM). The MRM, described in the Introduction, has good reliability and discriminant validity (Rogers et al., 2012). For the purposes of this investigation, the MRM was administered using standard instructions with a slight modification. Detainees were also asked to generate four consequences: (a) best possible consequence of waiving, (b) worst possible consequence of waiving, (c) best possible consequence of exercising, and (d) worst possible consequence of exercising. The modification involved asking defendants to determine whether the outcome was positive or negative, and then rate the probability of each outcome along with its importance to them. Probability was divided into quintiles ranging from $<20 \%$ to $>80 \%$. Importance was rated on a four point scale: $1=$ not important at all; $2=$ not very important; 3 = somewhat important; 4 = very important.

\section{Procedure}

The sample consisted of pretrial defendants detained at Cherokee County and Okmulgee County Detention Centers. These sites were chosen because of their proximity to Tulsa, Oklahoma so that data could be collected by the same research team. As a practical matter, we wanted to notify defense attorneys prior to the recruitment of pretrial defendants so they would have an opportunity to discuss their clients' participation in the study. We worked with the Oklahoma Indigent Defense System (OIDS), which represents all indigent defendants in these jails. OIDS notified their attorneys on a regular basis of which defendants would likely be contacted.

Because we sought a broad representation of pretrial defendants, the inclusion criteria were minimal: (a) representation by OIDS, (b) ability to speak English fluently, and (c) ability to 
provide written informed consent. The only exclusion criterion involved behavioral issues (i.e., uncooperative, inappropriate, or a potential security-risk).

Detainees who expressed an interest on a sign-up sheet were approached individually and provided with a more detailed description of the study. Those meeting the criteria described above were invited to participate in the study, after giving written informed consent in accordance with standards promulgated by the University of North Texas Institutional Review Board.

Following informed consent, participants were administered the research measures in a single session of two to three hours, with brief breaks to reduce fatigue. To maintain interest, different types of measures were interspersed; they included: psychological symptoms (i.e., SADS), cognitive (i.e., WASI, WAIT-II Reading and Listening subtests), and Miranda (i.e., MQ, MSS, MRM, MVS, and FRI) measures. After participants had completed all measures, they were debriefed and — as outlined in the informed consent — provided with nominal compensation (\$15) that was deposited into institutional funds accounts as an external incentive for active involvement in this research.

Researchers were comprised of two advanced graduate students, who received training and supervised administration of all measures applied. They had also been involved in previous Miranda studies and were part of the team that produced excellent interrater reliabilities for the SAMA measures.

\section{Results}

The sample was comprised of $59(73.8 \%)$ male and $21(26.2 \%)$ female pretrial defendants, ranging in age from 18 to 60 years $(M=32.79, \mathrm{SD}=10.57)$. Self-reported ethnic composition was 45.0\% Native American, 41.3\% European American, 7.5\% African American, 
5.0\% biracial, and 1.3\% Hispanic American. Although two participants reported their original language as non-English, they spoke English fluently.

All defendants reported having experienced at least two arrests, with an average of a total of 11.73 arrests $(S D=14.61)$. For their current charges, 32 had waived their rights and spoke with police, while 48 had exercised such rights. Although this was clearly non-significant ( $p$ s > $.20)$, we noted that those waiving their rights had a tendency towards greater reading comprehension $(d=0.32)$ but lower intellectual functioning $(d=-0.29)$ than those who did not waive them.

Regarding Miranda abilities, the failed recall of Miranda advisements (i.e., $<50 \%$ accurate) followed the predicted pattern with regard to reading levels: Easy $=24.1 \%$ failed; moderate $=45.6 \%$ failed; and difficult $=57.0 \%$ failed. For Miranda vocabulary, the majority of defendants failed to provide legally relevant definitions for seven words (i.e., coerced, coercion, demand, proceedings, incriminate, right, prosecution, terminate); the mean failure rate for these words was disturbingly high at $71.1 \%$. Similarly, six of the 25 MQ items were failed at least $50 \%$ of the time ( $M$ failure rate of $63.4 \%$ ). For example, about two-thirds (67.5\%), believed Miranda rights applied to non-custodial settings; this fallacy might lead arrestees to believe that their nonMirandized admissions were protected as long as a warning was not provided.

The capacity of these pretrial defendants to think clearly about their own reasons for waiving or exercising their rights is summarized in Table 1. Irrational reasons (i.e., psychotic thoughts or damaging inaccuracies) were almost never observed. A notable exception involved the benefits of exercising rights $(12.5 \%)$. For Constitutional protections, the percentages were troublingly modest with respect to long-term consequences. Only about one-half recognized the long-term risks of waiving rights (51.3\%), and even fewer (43.8\%) identified the long-term 
benefits of exercising rights. Interestingly, the risks of exercising rights focused mostly on immediate circumstances (e.g., angering police officers), which makes the most logical sense because long-term consequences (e.g., overcharging for the alleged offense) are not likely to occur in response to invoking Miranda rights.

Rogers and Drogin (in press) operationalized "likely-adequate reasoning"3 as the ability to generate reasons to invoke or waive Miranda rights, by taking into account the requirement of at least some long-term consequences. As summarized in Table 2, defendants without these longterm perspectives (the "questionable reasoning" group) evidenced marked difficulties in their verbal abilities, falling in the range traditionally classified as borderline intellectual functioning. ${ }^{4}$ The largest effect size $(d=0.92)$ for cognitive abilities was found for listening comprehension, which includes the capacity to remember and recall orally presented material. Importantly, the lowest grade level for likely-adequate reasoning was 6.80 , which is very close to the average ( $M$ = 6.97) for the questionable reasoning group. In this sample from general population (i.e., detainees not receiving mental health or other specialized services), psychological impairment does not discriminate between the two groups that differ only by several Global Assessment Function (GAF) points.

Predictably, pretrial defendants in the likely-adequate reasoning group evidenced stronger Miranda vocabulary and fewer Miranda misconceptions than their counterparts. Unexpectedly FRI scores remained virtually identical across the two groups. They are also very close to Grisso's (1998, p. 94) findings for adult offenders $(M=26.31, S D=3.26)$ and adult non-

\footnotetext{
${ }^{3}$ Although Rogers (2011) first described this category as "adequate," we prefer this more nuanced term as one that does not denote complete certainty.

${ }^{4}$ The American Psychiatric Association's Diagnostic and statistical manual of mental disorders (5 ${ }^{\text {th }}$ ed., 2013)currently DSM-5- no longer specifies a range of IQ scores when defining this category.
} 
offenders $(M=25.52, S D=3.27)$. Because of its use of hypothetical material, however, the FRI does not require defendants to reason about their own circumstances and criminal charges.

The primary objective of the research was to examine positive and negative consequences associated with defendants' Miranda decisions. Understandably, the majority of the defendants (43 or 53.8\%) could not think of any positive consequences of waiving their rights (see Table 3 ). More concerning were the responses of the $11(13.8 \%)$ who were unable to generate any positive consequences for exercising their Miranda rights. Using a cost-benefit analysis, the pretrial defendants generally weighed the decision to exercise Miranda $(M=24.41 ; S D=9.38)$ as significantly more valuable than the decision to waive Miranda $(M=19.46 ; S D=6.94) F(1,79)$ $=17.68, p<.001, d=0.60)$. However, overall averages obscure important differences.

Given the focus on knowing and intelligent waivers, defendants' case-specific reasons for waiving their Miranda rights were explored (see Appendix A). Knowledge of the right to counsel was compromised (a) directly for $10.2 \%$, who were unaware of their right to counsel, and (b) indirectly for $6.2 \%$, who were incognizant of free legal counsel for indigent defendants. The focus on intelligent waivers within the framework of reasoned choices (Godinez) is much more difficult to ascertain from the brief MRM responses. The two leading reasons for relinquishing rights to silence (21.9\%: better outcome by talking) and counsel (30.6\%: did not need legal expertise) could hardly be considered exemplars of reasoned decision-making. Still, case circumstances could arise where the decisions based on these rationales could appear quite reasonable (such as an informal resolution to marijuana possession). Likewise, other reasonsbeyond severe intoxication — must also be considered on a case-by-case basis. As a general matter, it would be naïve to assume that "explaining the circumstances" or "proclaiming innocence" would be advantageous to defendants, although such cases could occur. 
The overall appraisal scores (likelihood X desirability) were calculated for each defendant. Three groups emerged: (a) 44 (55.0\%) reasoned that exercising Miranda was the better decision, (b) 24 (30.0\%) reasoned that waiving Miranda was a better choice, and (c) 12 $(15.0 \%)$ concluded that both options were of equal value. However, actual waiver decisions were often not aligned with an examination of rational consequences. On the MRM, nearly half of the defendants who made a stronger case for exercising their rights ultimately chose to waive them (see Figure 1). The results are far more dramatic for those defendants who made a stronger case for waiving Miranda: Nearly four out of five (79.2\%) went against their own reasoning and exercised their rights.

\section{Discussion}

\section{Recall and Miranda Reasoning}

The Supreme Court of the United States has long presumed - if only by default — that adult offenders fully utilize whatever rational capacities they possess when it comes to rendering waiver decisions. In Berghuis v. Thompkins (2010), the Court reasoned that the prolonged interrogation of nearly three hours actually enhanced the suspect's reasoning and could result in a more informed decision:

Interrogation provides the suspect with additional information that can put his or her decision to waive, or not to invoke, into perspective. As questioning commences and then continues, the suspect has the opportunity to consider the choices he or she faces and to make a more informed decision, either to insist on silence or to cooperate. When the suspect knows that Miranda rights can be invoked at any time, he or she has the opportunity to reassess his or her immediate and long-term interests. (p. 2264) 
The Court is assuming that suspects are able to accumulate knowledge capably, rationally ascertain its importance, and competently reassess their decisional priorities. It also assumes that these rational processes are unaffected by the "one-sided, accusatory monologue by officers" (Weisselberg, 2010, p. 71) that is conducted within the typically oppressive confines of an interrogation room.

Findings from the current investigation are a far cry from Court's image of custodial suspects as information-integrating ratiocinators. In sharp contrast to this image, nearly half $(48.7 \%)$ did not even consider the long-term consequences of waiving their Miranda rights. To put this finding in context, Miranda warnings across American jurisdictions explicitly admonish that any statements by suspects will be used as evidence against them. Moreover, nearly all warnings (> 95\%; see Rogers, Hazelwood, Sewell, Harrison, \& Shuman, 2008) are further explicit in that this evidence will be used in subsequent trials and proceedings. Clearly, the defendants in the current study did not recall or use the information provided to them within minutes of their own Miranda advisements. On this point, a crucial distinction must be drawn between the terms "advised" and "educated." Yes, all defendants were advised of their rights, but only half were likely educated about their rights. ${ }^{5}$ The notion of the mind serving like an audio recorder — faithfully processing and storing information — has long been discarded as a fallacy (Neisser, 1985). Moreover, the interrogator's use of legalese may further impede recall, as documented by juror research comparing law students to a legally-naïve community sample (Brewer, Harvey \& Semmler, 2004).

The Supreme Court of the United States apparently opted for the audio-recorder presumption in the Thompkins case when it affirmed such decisions are rendered by a custodial

\footnotetext{
${ }^{5}$ An unknown percentage was previously informed of their rights; therefore, we cannot attribute the $50 \%$ to only their most recent Miranda advisement.
} 
suspect with "full understanding of his or her rights" (2010, p. 2262, emphasis added). As observed by Rogers et al. (2012, p. 6), the Court was virtually compelled to make this presumption in the "absence of any evidence to the contrary." In other words, no data appears to have been provided to the trial court regarding this particular defendant's inability to remember and apply the Miranda advisement to his case. Therefore, its finding was based on a presumption of full comprehension.

\section{Miranda Warnings and Miranda Misconceptions}

The Supreme Court of the United States in Florida v. Powell (2010) concluded that custodial suspects should be able to deduce correctly that they have the right to counsel during the interrogation, based on their having been provided before interrogation from a subsequent statement about the assertion of rights at "at any time you want during this interview" (p. 1197). The Court premised its ruling on the notion that defendants can both recall a Miranda advisement accurately and apply it rationally to their waiver decisions. ${ }^{6}$

Clearly, the Miranda Court did not intend Miranda advisements to be a proforma recitation meant simply to satisfy a "bureaucratic triviality" (Leo, 1998, p. 67). Instead, it fully expected that the warnings would serve some educative purpose of truly informing suspects of their Miranda rights — and by extension — rectifying serious misconceptions — that may nullify the intelligent prong of Miranda waivers. Unfortunately, recent research casts doubt on the effectiveness of Miranda warnings. Rogers, Fiduccia, Robinson, Steadham, and Drogin (2013) provided five different Miranda warnings asking each time for defendants' recall. The majority $(61.1 \%)$ of those with serious Miranda misconceptions failed to improve, despite this intensive exposure. Predictably, unimproved defendants evidenced marked deficits in verbal abilities as

\footnotetext{
${ }^{6}$ A mock crime study (Gillard, Rogers, Kelsey, Robinson, in press) utilizing college undergraduates found little difference when the Powell exclusion was used, because most of these educated participants failed to remember any time reference (i.e., "before" or "before and during") within five minutes of hearing the Miranda warning.
} 
well as limited capacity to define Miranda vocabulary and recall the content of Miranda warnings.

Custodial suspects are not apprised of the positive reasons for exercising their Miranda rights, although they might be expected to infer that remaining silent diminishes the likelihood of self-incrimination. Some suspects might reasonably conclude that presence of legal expertise may assist in their defense. In light of these considerations, it is very troubling that less than half of respondents $(43.8 \%)$ were unable to generate a single long-term reason for exercising their rights. Such reasons would include less likelihood of conviction and also plea discounts (i.e., less evidence leads to better deals; see Rogers \& Drogin, in press). About one-third (35.0\%) recognized only immediate benefits of exercising Miranda rights (e.g., stop questioning), whereas the remaining were divided between those providing no useful information $(8.8 \%)$ or suffering from dangerous misconceptions (12.5\%) that potentially undermined their waiver decisions. Commonsensically, defendants will not ask for defense attorneys if they wrongly believe that such access is conditioned upon adequate financial resources.

Exercising Miranda rights serves other advantages, recognized by the Supreme Court of the United States, but almost never disclosed to custodial suspects. The invoking of Miranda rights virtually ends the prolonged questioning and accusatorial statements, such as observed in the Thompkins case. In addition, the assertion of the right to counsel can yield other important advantages in reducing the "likelihood that the police will practice coercion" and ensuring that any statements by the accused are "rightly reported by the prosecution at trial" (Miranda, p. 470).

\section{Rational Decision-Making and Miranda Rights}


As we have described with respect to its stated reasoning in both Thompkins and Powell, the Supreme Court of the United States has explicitly presumed that custodial suspects will utilize whatever rational capacities they may have at their disposal. This presumption may reflect a tacit assumption that erecting a more complex standard could render an already over-burdened criminal justice system unworkable, should trial courts be compelled to conduct "sweeping inquiries into the state of mind of a criminal defendant who has confessed" (Colorado $v$. Connelly, 1986, p. 167). We tackled this overt presumption of rational decision-making in the context of knowing and intelligent Miranda waivers. Earlier sections of this Discussion addressed whether defendants engaged in information integration that might correct Miranda misinformation and misconceptions. This section delves into ratiocination, the reasoning process as it relates to Miranda-waiver decisions.

Psychologists may be guilty of something akin to the Court's audio-recorder fallacy whenever they presume that all custodial suspects conduct a formal, multi-layered rational analysis in reaching exercise or waive decisions. As outlined in the Introduction, articulated decisional models typically assume that defendants systematically evaluate the pros and cons attached to each decision, taking into account their likelihood and desirability. For most defendants, however, the process was nothing if not simple. They tended to generate only one positive and negative reason - if that — for each alternative at the time of the waiver decision. Within this decisional framework, they clearly weighed the negative consequences of waiving their rights as much greater $(d=1.09)$ than the positive consequences (see Table 3$)$. However, the weighing of consequences often had minimal impact on their actual decision-making.

\section{Future Directions and Concluding Thoughts}


The absence of bright-line legal standards for what constitutes a reasoned choice in the context of Miranda waiver decisions poses a formidable challenge for social-science researchers. The primary aims of the current study were (a) to examine how pretrial defendants determined whether to waive or assert Miranda in their own cases, and (b) to provide data on various reasoning abilities outlined in legal decision making models to determine their applicability to defendants' actual Miranda waiver decisions. Current findings are informative as a first step in examining decisional competence in the context of Miranda waiver decisions; however, further research is warranted to expand on the broad conclusions proposed here. Many other factors may contribute to defendants' critical decision to waive or assert their rights to silence and legal counsel. Future research could consider the potential impact of defendant characteristics, including (a) situational factors, (b) interrogative techniques, (c) severe mental disorders, (d) substance intoxication or withdrawal, (e) attentional abilities, and (f) the nature of legal charges with which a defendant is faced. More challenging to investigate would be pre-interrogation variables, such as specific accusatorial techniques. In addition, waiver decisions of defendants are likely to be strongly influenced by their perceptions of the evidence stacked against them when "caught red-handed" or identified by an eyewitness (see Gudjonsson \& Sigurdsson, 1999). The current study examined how defendant's weigh risks and benefits of Miranda waiver decisions, and a general conclusion from our findings suggests many defendants cast aside rational reasoning and make seemingly irrational legal decisions. Surprisingly, however, some defendants appeared to evaluate both waive and exercise options as comparable with minimal differences between them. In such instances, reasoning understandably plays a peripheral role in defendants' decision-making. In other instances, emotions appear to be the overriding factor. In our review of case law, emotions overriding rational abilities appear insufficient as the basis of 
an impaired "intelligent" waiver. If such cases do occur-at least in the absence of sound empirical research—it is quite possible that the Supreme Court of the United States will adopt reasoning similar to that conveyed in Connelly (1986, pp. 165-166), to the effect that trial courts should not be required to "divine a defendant's motivation." 


\section{References}

Adams v. United States, 317 U.S. 269 (1942).

American Psychiatric Association. (2013). Diagnostic and statistical manual of mental disorders (5th ed.). Arlington, VA: American Psychiatric Publishing.

Berghuis v. Thompkins, 130 S.Ct. 2250 (2010).

Blackwood, H. L. (2009). Miranda reasoning and competent waiver decisions: Are models of legal decision making applicable? (Unpublished doctoral dissertation). University of North Texas, Denton, TX.

Bonnie R. J. (1992). The competence of criminal defendants: A theoretical reformulation. Behavioral Sciences and the Law, 10, 291-316. doi: 10.1002/bsl.2370100303

Bonnie, (1993). The competence of criminal defendants: Beyond Dusky and Drope. University of Miami Law Review, 47, 539.

Brewer, N., Harvey, S., \& Semmler, C. (2004). Improving comprehension of jury instructions with audio-visual presentation. Applied Cognitive Psychology, 18, 765-776. doi:10.1002/acp.1036

California v. Prysock, 453 U.S. 355 (1981).

Colorado v. Connelly, 479 U.S. 157 (1986).

Colorado v. Spring, 479 U.S. 564 (1987).

Edwards v. Arizona, 451 U.S. 477 (1981).

Escobedo v. Illinois, 378 U.S. 478 (1964).

Fare v. Michael C., 442 U.S. 707 (1979).

Florida v. Powell, 130 S.Ct. 1693 (2009). 
Fromme, K., Katz, E., \& Rivit, K. (1997) Outcome expectancies and risk-taking behavior. Cognitive Therapy and Research, 21, 421-442. doi: 0147-5916/97/0800-0421\$12.50/0

Gillard, N. D., Rogers, R., Kelsey, K. R., Robinson, E. V. (in press). An investigation of implied Miranda waivers and Powell wording in a mock-crime study. Law and Human Behavior.

Godinez v. Moran, 509 U.S. 389 (1993).

Goldstein, N. E., Zelle, H., \& Grisso, T. (2012). Miranda Rights Comprehension Instruments (MRCI). Sarasota, FL: Professional Resource Press.

Grisso, T. (1981). Juveniles' waiver of Miranda rights: Legal and psychological competence. New York: Plenum.

Grisso, T. (1997). The competence of adolescents as trial defendants. Psychology, Public Policy, and Law, 3, 3-32. doi: 1076-8971/97

Grisso, T. (1998). Instruments for assessing understanding and appreciation of Miranda rights. Sarasota, FL: Professional Resources Press Inc.

Grisso, T. (2003). Evaluating competencies: Forensic assessments and instruments ( $2^{\text {nd }}$ ed.). New York: Kluwer Academic.

Gudjonsson, G. H., \& Sigurdsson, J. F. (1999). The Gudjonsson Confession QuestionnaireRevised (GCQ-R): Factor structure and its relationship with personality. Personality and Individual Differences, 27, 953-968.

Hilgendorf, E. L., \& Irving, B. (1981). A decision-making model of confessions. In M. A. LloydBostock (Ed.), Psychology in legal contexts. Applications and limitations (pp. 67-84). London: Macmillan Press.

Iowa v. Tovar, 541 U.S. 77 (2004).

Johnson v. Zerbst, 304 U.S. 458 (1938). 
Kiernan, R. J., Mueller J., Langston J. W., Van Dyke C. (1987). The Neurobehavioral Cognitive Status Examination: A brief but differentiated approach to cognitive assessment. Annals of Internal Medicine, 107, 481-485.

Leo, R. A. (1992). From coercion to deception: The changing nature of police interrogation in America. In R. A. Leo \& G. C. Thomas (Eds.). The Miranda debate: Law, justice, and policing (pp. 65-74). York, PA: Maple Press.

Miranda v. Arizona, 384 U.S. 436 (1966).

Moran v. Burbine, 475 U.S. 412 (1986).

Neisser, U. (1985). On the trail of the tape-recorder fallacy. Social Action \& the Law, 11(2), 3539.

People v. Bernasco 562 N.E.2d 958 (Ill. 1990).

Rogers, R. (2005). Miranda Statements Scale. Unpublished measure, University of North Texas, Denton, TX.

Rogers, R. (2006). Miranda Acquiescence Scale (MAQ). Unpublished measure, University of North Texas, Denton, TX.

Rogers, R. (2008). A little knowledge is a dangerous thing . . Emerging Miranda research and professional roles. American Psychologist, 63, 776-787. doi:10.1037/0003066X.63.8.776

Rogers, R. (2011). Getting it wrong about Miranda rights: False beliefs, impaired reasoning, and professional neglect. American Psychologist, 66, 728-736. doi: 10.1037/10024988

Rogers, R., Correa, A. A., Hazelwood, L. L., Shuman, D. W., Hoersting, R., \& Blackwood, H. L. (2009). Spanish translations of Miranda warnings and totality of the circumstances. Law and Human Behavior, 33, 61-69. doi: 10.1007/s10979-0018-9129-9 
Rogers, R., \& Drogin, E. Y. (in press). Challenging and preserving Mirandized statements: Successfully navigating the psychological and legal issues. Chicago: American Bar Association Publishing.

Rogers, R., Fiduccia, C. E., Drogin, E. Y., Steadham, J. A., Clark, J., \& Cramer, R. J. (2013). General knowledge and misknowledge of Miranda rights: Are effective Miranda advisements still necessary? Psychology, Public Policy, and Law, 19, 432-442. doi:10.1037/a0033964

Rogers, R., Fiduccia, C. E., Robinson, E. V., Steadham, J. A., \& Drogin, E. Y. (2013). Investigating the effects of repeated Miranda warnings: Do they perform a curative function on common Miranda misconceptions? Behavioral Sciences \& the Law, 31, 397410. doi:10.1002/bsl.2071

Rogers, R., Harrison, K. S., Hazelwood, L. L., \& Sewell, K. W. (2007). Knowing and intelligent: A study of Miranda warnings in mentally disordered defendants. Law and Human Behavior, 31, 401-418. doi: 10.1007/a10979-006-9070-8

Rogers, R., Harrison, K. S., Rogstad, J. E., LaFortune, K. A., Hazelwood, L. L. (2010). The role of suggestibility in determinations of Miranda abilities: A study of the Gudjonsson Suggestibility Scales. Law and Human Behavior, 34, 66-78. doi: 10.1007/s10979-0099186-8

Rogers, R., Harrison, K. S., Shuman, D. W., Sewell, K. W., \& Hazelwood, L. L. (2007). An analysis of Miranda warnings and waivers: Comprehension and coverage. Law and Human Behavior, 31, 177-192. doi: 10.1007/s10979-006-9054-8 
Rogers, R., Hazelwood, L. L., Sewell, K. W., Blackwood, H. L., Rogstad, J. E., \& Harrison, K. S. (2009). Development and initial validation of the Miranda Vocabulary Scale. Law and Human Behavior, 33, 381-392. doi: 10.1007/s10979-008-9159-3

Rogers, R., Hazelwood, L. L., Sewell, K. W., Harrison, K. S., \& Shuman, D. W. (2008). The language of Miranda warnings in American jurisdictions: A replication and vocabulary analysis. Law and Human Behavior, 32, 124-136. doi: 10.1007/s10979-007-9091-y

Rogers, R., Hazelwood, L. L., Sewell, K. W., Shuman, D. W., \& Blackwood, H. L. (2008). The comprehensibility and content of juvenile Miranda warnings. Psychology, Public Policy, and Law, 14, 63-87. doi: 10.1037/a0013102

Rogers, R., Jackson, R. L., Salekin, K. L., \& Neumann, C. S. (2003). Assessing Axis I symptomatology on the SADS-C in two correctional samples: The validation of subscales and a screen for malingered presentations. Journal of Personality Assessment, 10, 344351.

Rogers, R., Rogstad, J. E., Gillard, N. D., Drogin, E. Y., Blackwood, H. L., \& Shuman, D. W. (2010). “Everyone knows their Miranda rights:” Implicit assumptions and countervailing evidence. Psychology, Public Policy, and Law, 16, 300-318. doi:10.1037/a0019316

Rogers, R., Sewell, K. W., Drogin, E. Y., \& Fiduccia, C. E. (2012). Standardized assessment of Miranda abilities (SAMA). Lutz, FL: Psychological Assessment Resources.

Rogers, R., \& Shuman D. W. (2005). Fundamentals offorensic practice: Mental health and criminal law. New York: Springer Publishing.

Sheehan, D. V., Sheehan, S. H., Shytle, R. D., Bannon, Y., Rogers, J. E., Milo, K. M., Stock, S. L., \& Wilkinson, B. (2010). Reliability and validity of the Mini International 
Neuropsychiatric Interview for Children and Adolescents (MINI-KID). Journal of Clinical Psychiatry, 71, 313-326. doi: 10.4088/JCP.09m05305whi

Spitzer, R. L., \& Endicott, J. (1978). Schedule of affective disorders and schizophrenia ( $3^{\text {rd }}$ ed.). New York: Biometrics Research.

Strathman, A., Gleicher, F., Boninger, D.S., \& Edwards, S. (1994). The consideration of future consequences: Weighing immediate and distant outcomes of behavior. Journal of Personality and Social Psychology, 66, 742-752. doi: 022-3514/94

United States v. Ruiz, 536 U.S. 622 (2002).

Wechsler, D. (1999). Wechsler abbreviated scale of intelligence. San Antonio, TX: Psychological Corporation.

Wechsler, D. (2002). Wechsler individual achievement Test ( $2^{\text {nd }}$ ed.). San Antonio: Psychological Corporation.

Weisselberg, C. (2010). The future of the Miranda ruling. In L. S. Wrightsman \& M. L. Pitmann (Eds.), The Miranda ruling: Its past, present, and future (pp. 155-172). New York: Oxford University Press. 
Table 1

Defendants' Abilities to Reason on the MRM about Waiving and Exercising Rights

\begin{tabular}{|c|c|c|c|c|c|c|c|c|}
\hline \multirow[b]{4}{*}{ Reasoning } & \multicolumn{8}{|c|}{ Types of Responses } \\
\hline & \multirow{2}{*}{\multicolumn{2}{|c|}{ Irrational }} & \multirow{2}{*}{\multicolumn{2}{|c|}{$\begin{array}{l}\text { Vague / no } \\
\text { information }\end{array}$}} & \multirow{2}{*}{\multicolumn{2}{|c|}{$\begin{array}{l}\text { Immediate } \\
\text { Consequence }\end{array}$}} & \multirow{2}{*}{\multicolumn{2}{|c|}{$\begin{array}{l}\text { Future } \\
\text { Consequence }\end{array}$}} \\
\hline & & & & & & & & \\
\hline & $n$ & $\%$ & $n$ & $\%$ & $n$ & $\%$ & $n$ & $\%$ \\
\hline Benefit of waiving & 1 & 1.3 & 3 & 3.8 & 32 & 40.0 & 44 & 55.0 \\
\hline Risk of waiving & 0 & 0.0 & 8 & 10.0 & 31 & 38.8 & 41 & 51.3 \\
\hline Benefit of exercising & 10 & 12.5 & 7 & 8.8 & 28 & 35.0 & 35 & 43.8 \\
\hline Risk of exercising & 1 & 1.3 & 4 & 5.0 & 53 & 66.3 & 22 & 27.5 \\
\hline
\end{tabular}


Table 2

Differences in Miranda Reasoning on Cognitive, Clinical, and Miranda Variables

\begin{tabular}{|c|c|c|c|c|c|c|c|}
\hline \multirow[b]{3}{*}{ Variable } & \multirow{2}{*}{\multicolumn{2}{|c|}{$\begin{array}{c}\text { Likely Adequate } \\
\text { Reasoning }(n=22)\end{array}$}} & \multirow{2}{*}{\multicolumn{2}{|c|}{$\begin{array}{c}\text { Questionable } \\
\text { Reasoning }(n=23)\end{array}$}} & \multirow[b]{3}{*}{$F$} & \multirow[b]{3}{*}{$p$} & \multirow[b]{3}{*}{$d$} \\
\hline & & & & & & & \\
\hline & $M$ & $S D$ & $M$ & $S D$ & & & \\
\hline Verbal IQ & 91.05 & 10.07 & 84.17 & 11.98 & 4.32 & .04 & 0.62 \\
\hline Performance IQ & 98.73 & 13.22 & 91.83 & 14.22 & 2.84 & .10 & 0.50 \\
\hline Reading comprehension & 8.84 & 2.95 & 6.97 & 2.98 & 4.44 & .04 & 0.63 \\
\hline Listening comprehension & 10.18 & 2.06 & 7.61 & 3.39 & 9.33 & .004 & 0.92 \\
\hline GAF & 71.86 & 8.51 & 68.52 & 10.11 & 1.43 & .24 & 0.36 \\
\hline MSS & 66.29 & 18.50 & 62.68 & 23.69 & .32 & .57 & 0.17 \\
\hline MVS & 73.11 & 14.86 & 61.59 & 20.98 & 4.47 & .04 & 0.63 \\
\hline MQ & 73.09 & 8.74 & 68.00 & 9.18 & 3.62 & .05 & 0.58 \\
\hline FRI & 25.95 & 2.66 & 25.43 & 3.09 & .36 & .55 & 0.18 \\
\hline
\end{tabular}

Note. Verbal/Performance IQ = WASI composite scores; Reading/Listening Comprehension = WIAT-II grade equivalent; GAF = Global Assessment of Functioning; MSS = Miranda Statements Scale $(\%$ correct $) ;$ MVS = Miranda Vocabulary Scale $(\%$ correct $) ; \mathrm{MQ}=$ Miranda Quiz $(\%$ correct $) ; \mathrm{FRI}=$ Function of Rights in Interrogation (total score). 
Table 3

Defendants' Overall Appraisals of Consequences Associated with Miranda Waiver Decisions

Overall Appraisal $^{\mathrm{a}}$

\begin{tabular}{|c|c|c|c|c|c|c|c|c|c|}
\hline \multirow[b]{2}{*}{ Decision } & \multicolumn{3}{|c|}{ Positive Consequences } & \multicolumn{3}{|c|}{ Negative Consequences } & \multirow[b]{2}{*}{$F$} & \multirow[b]{2}{*}{$p$} & \multirow[b]{2}{*}{$d$} \\
\hline & Excluded $^{\mathrm{b}}$ & $M$ & $S D$ & Excluded $^{\mathrm{b}}$ & $M$ & $S D$ & & & \\
\hline Waive rights & 43 & 9.38 & 5.41 & 0 & 15.13 & 5.19 & 10.07 & .003 & 1.09 \\
\hline Exercise rights & 11 & 13.16 & 5.82 & 13 & 14.66 & 5.19 & 2.32 & .13 & -0.27 \\
\hline
\end{tabular}

${ }^{\mathrm{a} O v e r a l l}$ appraisal $=$ likelihood $\mathrm{X}$ desirability.

bThis column represents the number of defendants, who were excluded due to reporting "there are none" when asked about perceived consequences for Miranda waiver or non-waiver decisions (i.e., their overall appraisal would equal zero). 


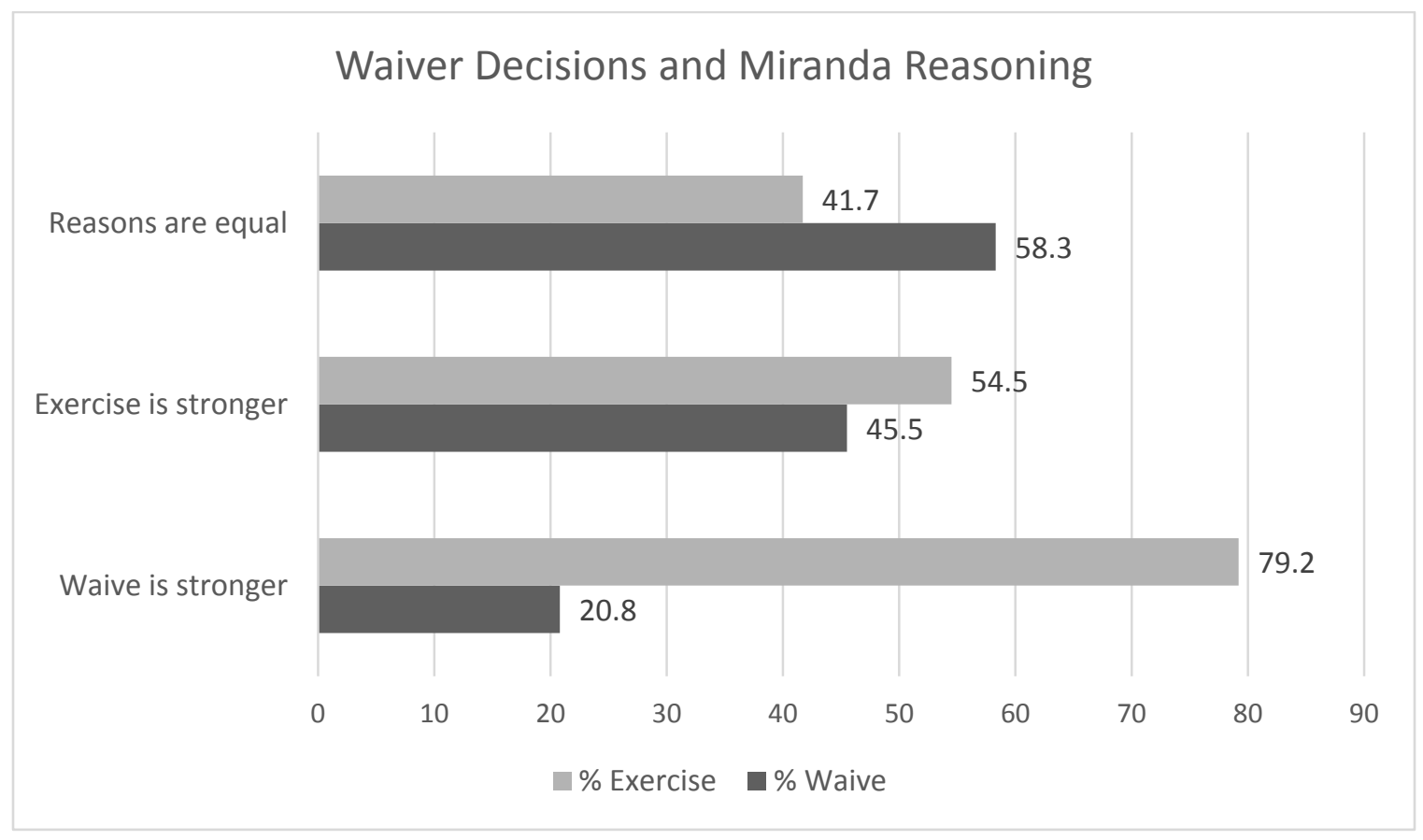

Title of Figure 1: Defendants' Reasoning and Actual Decisions regarding Miranda Waivers 
Appendix A

Defendants' Case-Specific Reasons for Waiving their Miranda Rights

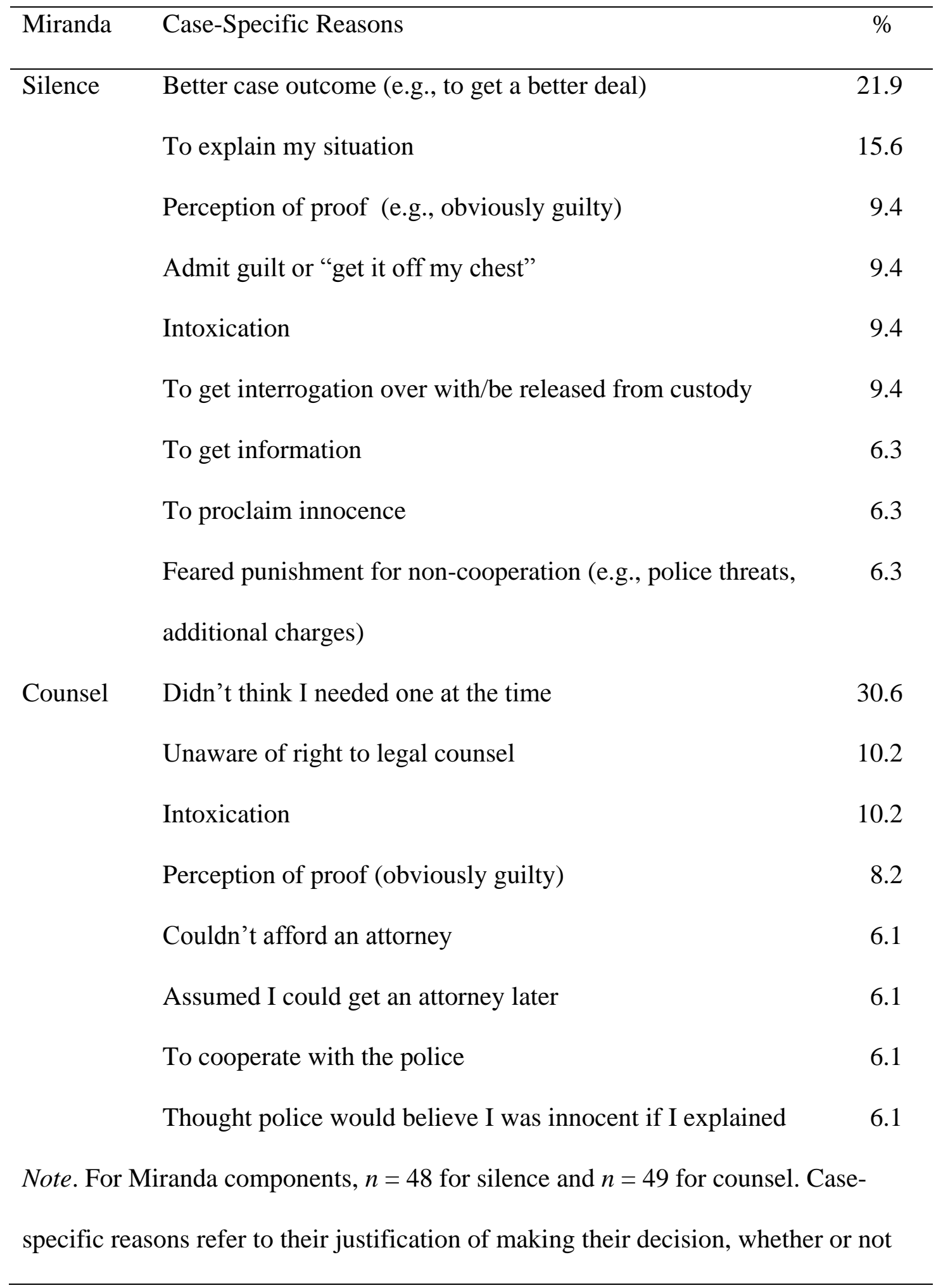


they followed through on it. Reasons are not included if used by less than $5 \%$ of defendants. 